\title{
Technology for Sustainable HRM: An Empirical Research of Health Care Sector
}

\author{
A.Jagan.Mohan. Reddy, Ridhi Rani, Varnika Chaudhary
}

\begin{abstract}
In a highly competitive world of today characterised by VUCA (Volatility Uncertainty Complexity and Ambiguity) environment organizations are striving to achieve excellence with standard business practices. Given the international mantra of cost quality \& service companies need to adopt technology in a proactive manner by collaborating with IT department. Traditionally $\mathrm{HR}$ and IT have operated as distinct units. But with the changing times there is an urgent need to adopt technology for improving the productivity of human resources thereby contributing to the sustainable organizational development. So a close collaboration between these two departments is called for.
\end{abstract}

Some of the HR professionals assume that technology will fix all their problems i.e. By moving to cloud the outdated HR operating model and disconnected data sourcing issues will get resolved. But HR professionals will be committing a grave mistake if they think that the technology will be a panacea to all HR problems. In other words, the key is about how the technology is applied and not the acquisition of technology.

In the prevailing competitive environment there is every need to understand appreciate the behaviour of the employees so that required initiatives could be taken for obtaining outstanding performance from these valuable human resources. In this regard technological tools like HR Analytics(HRA) Artificial Intelligence (AI) come very handy for getting valuable insights into human behaviour. Further application of these tools helps in effective decision making thereby contributing to the accomplishment of organization goals. Application of HRA and AI apart from facilitating decision making also helps in integrating Human Resource with other business activities.

The paper focusses on understanding how HR analytics helps in sustainable human resource management by providing insights into elementary $H R$ processes and behaviours. It also correlates well with current HRA/AI trends in general and health care sector in particular. Needless to say this will be a ready reference for any future study into role of data analytics/Artificial intelligence in Human Resource Management.

Key Words - Sustainability HR Analytics Health Care Sector Data Management Artificial Intelligence Algorithms Technology for Sustainable HRM: An Empirical Study of Healthcare Sector

\section{INTRODUCTION}

"If you can't measure it you can't improve it"- Peter Drucker.

Globalisation and technological development caused dramatic changes forcing transformation in Human Resource Management (HRM) as well. Further with rapid technological developments taking place increasing collaboration is called for between IT and HR departments

Revised Manuscript Received on August 05, 2019.

A.Jagan.Mohan. Reddy, Assistant Professor, Symbiosis Institute of Business Management, Hyderabad, Telangana, India.

Ridhi Rani, Assistant Professor, Symbiosis Institute of Business Management, Hyderabad, Telangana, India. (ridhi.rani@sibmhyd.edu.in)

Varnika Chaudhary, Assistant Professor, Symbiosis Institute of Business Management, Hyderabad, Telangana, India.

which hitherto functioned in silos. Given the equal accessibility affordability and availability of all other resources it is the only talented Human resources which can provide the required cutting edge for the organisations not only to survive but prosper as well. As such there is an urgent need for applying technology like HR Analytics AI for gaining crucial insights into human behaviours for sustainable Human Resource Management.

Several studies have confirmed the contribution of HRM to organizational performance. For instance, Human resource activities are only related to Financial outcomes (Boudreau 2003). (1) Integration of technology such HRA and AI through sustainable HRM practices will definitely help the organizations in their pursuit of excellence. And understanding behaviour of employees in health care sector helps the hospital authorities to take required action. Because being a service sector, employees by their displayed behaviour make a lot of difference in serving the patients.

Human beings are the most important part of health care Industry. Machines and gadgets which are integral parts of health care require the human touch expertise and commitment for their full utility and application in delivery of health care. The objective of the Human Resource Management (HRM) policy is to attract hire develop \& retain talented human resource by designing best of compensation structure. And organization also need to create a learning culture in hospitals.

The role of HRM has changed in the past few years from administrative to value adding function including in healthcare organization. There are many challenges prevailing in Healthcare sector such as Leadership Development Change Management Effective Hiring Challenge Performance management and appraisals as well as Rewards and recognition.

HRM contributes to the achievement of the organization's pre-defined objectives. Gone are those days where organizations purpose was to make profit only. But of late not only there is a loud talk but realisation too in many circles that the need of the hour is about triple bottom line People Profit and Planet. Given the importance of HR and its immense contribution to organisations growth increasing attention is being paid to the health and wellbeing of the people. As a satisfied healthy and happy employee is a boon to the organization in terms of increased commitment and productivity. The need for sustainability in HRM practices arose because of its importance (given equal affordability accessibility and availability of all other resources) and need to sustain this precious resource. 
The paper focusses on understanding how HR analytics helps sustainable human resource management by providing insights into elementary HR processes and behaviours. It also correlates well with current HR analytics /Artificial intelligence trends in general and health care sector in particular. Needless to say this will be a ready reference for any future study into role of data analytics and Artificial intelligence in Human Resource Management.

\section{A. Objectives of The Paper}

To discuss the importance of application of technology such as HR Analytics and Artificial Intelligence for improving HRM practices.

To briefly look at the earlier studies relating to sustainable HRM practices including data driven decision making processes.

Application of analytical tools in health care sector.

\section{B. Research Methodology}

This is an exploratory-cum-empirical study to understand the importance of applying HRA/AI for better HRM in general and in health care sector in particular. The raw data utilized for analysis in this paper belongs to Pharmaceutical Organization / Super speciality Hospitals (Names aren't disclosed for privacy concern). Furthermore, the decision to examine HR Analytics through the lens of innovation adoption is also established through this paper with the latest advances in theories concepts and examples regarding why organization adopt analytical practices for sustainability. The concept of sustainability is sincerely integrated in the study towards HR analytics.

\section{LITERATURE REVIEW}

'HR Analytics' represents a new innovative tool used for troubleshooting the HR issues even though it has been in news for many years. Companies have benefited a lot especially in the areas of attrition analysis talent segmentation and retention. Lawler Levenson and Boudreau (2004) (1) distinguish 'Analytics' as separate from 'HR metrics'. Analytics are statistical techniques that can be used to show the impact of HRM activities. [Lawler et al. 2004]. Indeed, Bassi [2011] (2) argues that HR analytics consists of an array of tools and technologies ranging from the simple reporting of HRM metrics all the way up to predictive modelling and can be considered both as 'systematically reporting on an array of HR metrics' or more sophisticated solutions based on 'predictive models' and 'what-if scenarios'.

Jac Fitz- Enz, a HR analytics expert, suggest HR to master the art of expressing its activity in numbers, including the value it adds.(Fitz-Enz J. 2010) (3)(4). This evolution changes the role of the HR function and positions it as a value-added partner that contributes to the strategic goals of its organization. Hence to define it HR Analytics provides a data-driven framework for solving workforce problems using existing information to drive new insights. The researcher has tried to see this from the lens of compensation based metrics and tried to assess its effectiveness by using the techniques of trend analysis and salary benchmarking.
HR analytics estimates can be divided into four namely Descriptive; Diagnostic; Predictive and Prescriptive measures.

Descriptive analytics analyses the real -time and historical data and provides insights on how to approach the future. It provides reasons for the success or failure in the past. For instance, dashboard will show no of sales people people who have left the organization over the past year or trend analysis of the workforce to understand current situation based upon past data.(5)

Take for instance, the results that a business gets from the web server through Google Analytics tools. These help understand promotional campaign launched was successful or not. Diagnostic analytics reveals the causes of the events. For instance, a graphic report showing heavy attrition because of reasons like low job satisfaction to higher base salaries offered by competitors.

Predictive analytics, as the name suggests, based on the past data patterns and trends, informs business about what could happen in the future. Accordingly, organisation can plan to accomplish the desired goals. For instance, Google's mathematical algorithm predicting employees most likely to leave the organisation. Prescriptive analytics could be used by the company for possible outcomes using simulation and optimization.(6)

The summation and execution of all these measures for the functioning of different areas of HRM generates sustainability for an organization's operations. Specially from People's point of view it is extremely important to know it. The evidence generated at each level of HR analytics helps in proof based decision making and the company's board can rely upon the data without any question towards the authenticity of HR department's decision. This data quotient bridges the gap between current position/status of business and an organization's visions/goals.

\section{A. Technology for Sustainable HRM practices in}

\section{Health care sector}

For a better understanding of the HR problems in health care sector, it is important to understand the recent trends in the health care sector. One of the major trend in the healthcare sector is that labour costs are rising faster than the expert physicians who play a major role in the patient turnout. If inflation persists it will lead to increase in the equipment's costs and pre and post-operative care as well. The aging baby boomers on the other hand have also the advantage of getting rehired their net worth increases and feel more secure about the economic position. Another aspect is that whether it will have an effect on productivity as well. It will also lead to job creation in the sense that more support staff will be required to improve the productivity of the care givers. 
Let us look at some trends in the health care sector

Trends in the health care sector related to Human Resources are as follows:

- Monitoring staff vacancies turnover and project retirements

- $\quad$ Tracking the recruiting efforts and analysing costs to fill vacancies.

- $\quad$ Looking for new delivery models and technologies to improve productivity of the existing workforce.

- $\quad$ Earning power is greater in a hospital-based setting than private practice which is very important for physicians. So a well laid down compensation structure is must for practicing physicians and surgeons.

- Even the hospitals have the highest expectations from highly paid personnel to perform some administrative roles.

- Compensation arrangements between hospitals and physicians involve quid pro quo elements. It also depends on the availability of talent progression aspect in the health care sector.

All the above mentioned visible trends in the health care sector can be very well carried out by using the HR analytics tools and reporting mechanism. Through the dashboards prepared for manpower a comparison can be on the compensation hiring retention and development policies of the hospitals and super speciality hospitals. It will also lead to better decision making.

Another important factor to be considered is the decision making in HR which was in most of cases was taken on the basis of gut feeling and intuition. Now it is most of the time taken through data.

One important thing HR professionals need to understand is that the technology could be used to make better decisions. For instance, Aurora Health Care system saved \$6 million annually by using prescriptive analytics to reduce readmission rates by $10 \%$. ( 7)

Data-driven decision making (DDDM) (8 ) involves making decisions that are backed up by hard data rather than making decisions that are intuitive or based on observation alone. It helps in the health care sector in order to streamline the process of patient management pain management scheduling surgeries manpower requirement availability of the equipment and also compensation matters. As business technology has advanced exponentially in recent years' data-driven decision making has become a much more fundamental part of all sorts of industries including important fields like medicine transportation and equipment manufacturing.

PERSOLKELLY (2019) (9) survey explored the readiness of organizations and employees for an inclusive workforce and technology-driven workplace. The findings of this survey, being released in two parts, are as under:

- One-third (36\%) and one-fifth (21\%) of respondents in India reported that their companies have adopted automation and AI respectively.

- Two-thirds $(68 \%)$ of respondents felt that automation and AI will help to increase their work efficiency and

- $\quad$ More than half (57\%) said it will help to increase their company's bottom line.
- Increasing the use of automation and AI in the workplace can result in increased employee satisfaction but organizations also need to allay employees' concerns.

Now we will see the usage of technology and analytical tools in healthcare sector at each HRM function cited with few examples and data analysis

\section{DATA ANALYSIS AND FINDINGS}

One of the researchers has closely observed the HR practices in a super speciality hospital and collected data to understand the trends and patterns in that area. In addition to this data of Pharmaceutical organization has also been used. In other words, both primary and secondary data have been used for the analysis.

A. Analysis of Emotional Labour with respect to Employees time period with Organization

There is a misconception in few quarters that HR is a cost centre only and has no impact on the organization's performance. This is because there is a lack in assessing the real impact of the human resource activities and benefits organization gets out of it. This is all the more relative in the health care sector where the salaries of the health care professional should be theoretically commensurate with the emotional labour involved in the jobs they do. The question arises as to what are the motivators and hygiene factors for these professionals and what leads to job involvement and attain maximum job satisfaction.

\section{Methodology}

In order to understand the effect of emotional labour on the time period (years) of employees stay with the company. We selected four variables from a structured data set of a Pharmaceutical Organization (Not named for privacy concern) for analysis.

Size of Data set - 1470 observation

Number of variables- 43 (Independent)1(Dependent)

Independent variable - Job involvement Job satisfaction and Relationship Satisfaction

Dependent variable - Years in the Company

Hypothesis:

Null Hypothesis (H0) - There is no relationship between the Job Involvement (Independent Variable) and years in the company (Dependent variable)

Alternate Hypothesis (H1) - There is no relationship between the Job Involvement (Independent Variable) and years in the company (Dependent variable)

Data Analysis Projection: 
Table 1: Showing the Summary Output

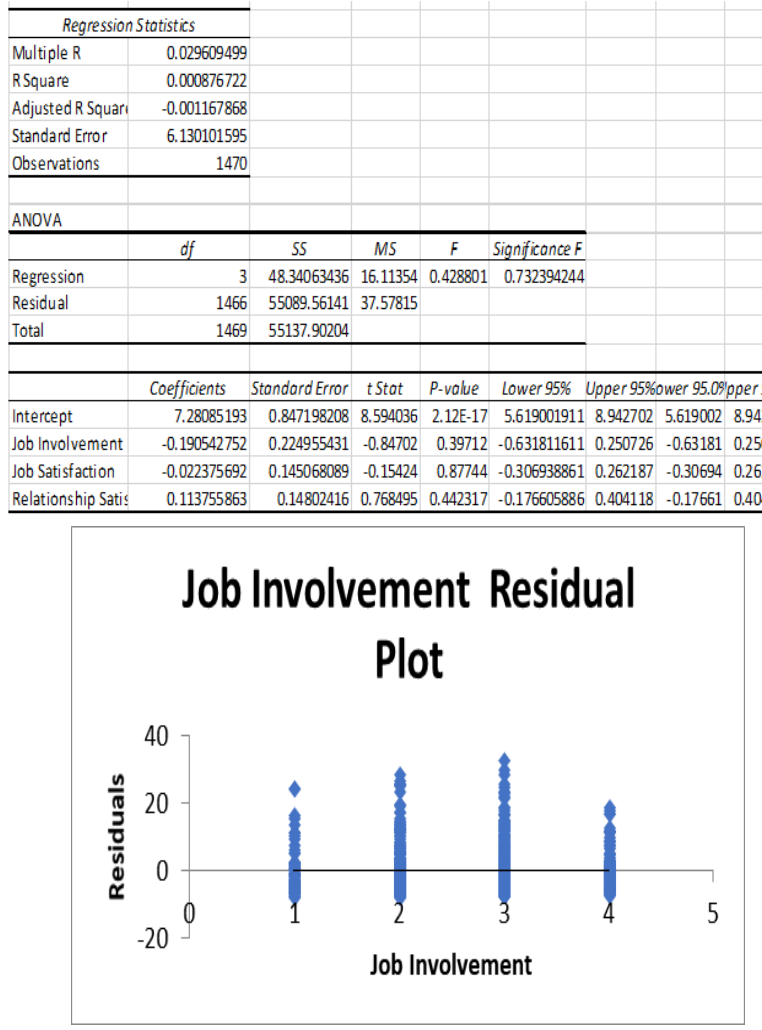

Relationship Satisfaction Residual Plot

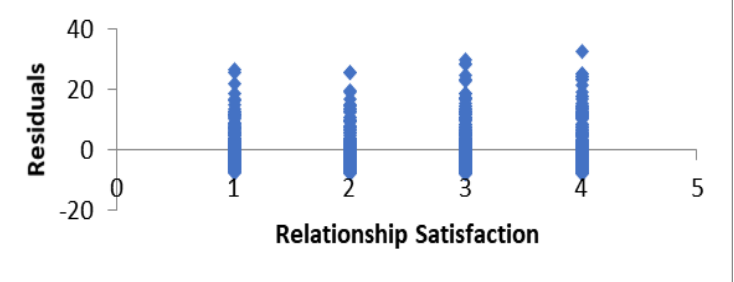

\section{Job Satisfaction Residual Plot}

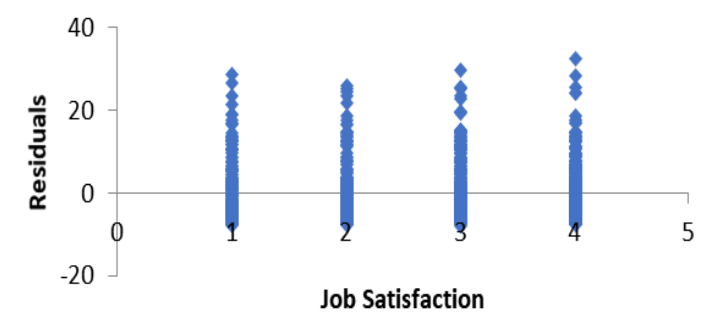

Graph 1 Job involvement Job satisfaction and Relationship Satisfaction with years at the company

Null Hypothesis $(\mathrm{H}=0)$ considered there is no relation between Dependent and Independent variables. Dependent variable isn't going to get effected by Independent variable.

Findings: - Analysis of Emotional Labour with respect to Employees time period with Organization

The data projected a significance level of more than 0.05 i.e. 0.73 (which is greater than 0.05 ) at the confidence level of $95 \%$ hence we do not reject the null hypothesis.
Therefore, the time period (years) of employees stay with the company is not highly dependent on the emotional labour factors such as Job Satisfaction Relationship Satisfaction etc. There is a high possibility that others factors such as career opportunities percentage hike in Income or additional monetary and non-monetary benefits have kept them motivated to stay with the company.

\section{B. Trend Analysis of Past Years Compensation}

Methodology: - For performing this analysis three year pay data has been collected for each department. The average pay for each department is ascertained and prognosis is utilized to determine the running trend of pay department wise as well as year wise.

\section{DATA ANALYSIS PROJECTION}

\section{TREND ANALYSIS}

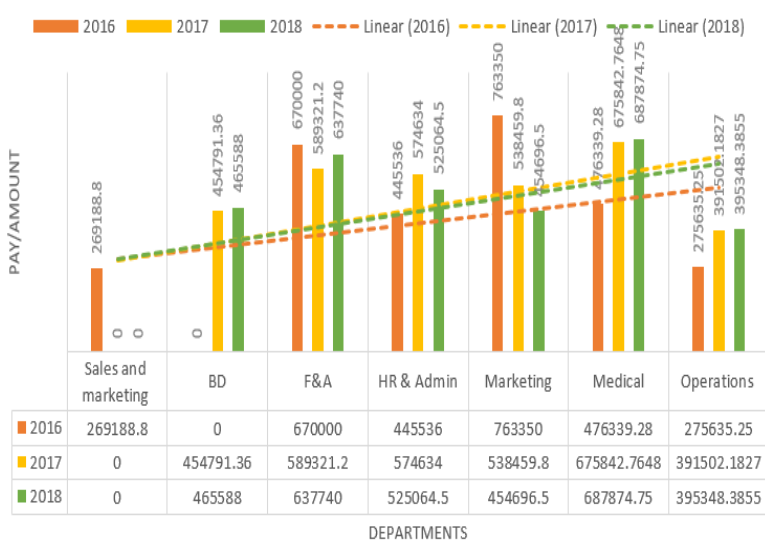

Graph 2: Trend Analysis

Findings:- Trend Analysis of Past Years Compensation

The trend line is in progression year after year hence it is a positive aspect with respect to pay per year.

At the same time, we see considerable difference between pay in 2017 and 2018 whereby in departments like HR and Marketing the pay average of 2017 is higher than 2018.

This also provides an insight of compensation structure within different units of an Organization and analysis of pays in which all departments are lagging based upon current market trends.

As this is an authentic data it resulted in understanding of few important facts too such as Bonus pay disparity which was promised to HR department employees and not being given by the company (as recorded through discussion with employees). This company faced heavy attrition afterwards (Observed by inside sources).

\section{Salary Structure Modelling}

3.3.2 Methodology: In order to perform salary structure modelling through Regression Analysis Employee data is segregated into different grades/levels designation wise. Their market median (salary) is researched through secondary data sources. Thereafter Regression analysis is performed to decide upon salary max and salary min on a specific bandwidth. Bandwidth can vary depend upon 
organization. Hereby data of only one level is presented as an example.

Data Projection

Table 2: Salary Structure Modelling

\begin{tabular}{|c|l|c|c|}
\hline \multicolumn{4}{|c|}{ LEVEL 5 REGRESSION ANALYSIS } \\
\hline \multirow{2}{*}{ CODE } & \multicolumn{1}{|c|}{ DESIGNATIONS } & GRADE/LEVEL & $\begin{array}{c}\text { MARKET } \\
\text { MEDIAN } \\
\text { (SALARY) }\end{array}$ \\
\hline 1 & DATA ENTRY OPERATOR & 5 & 123962 \\
\hline 2 & CHAUFFER & 5 & 178486 \\
\hline 3 & OT ASSISTANT & 5 & 196041 \\
\hline 4 & JUNIOR ADMIN & 5 & 248427 \\
\hline 5 & OT TECHNICIAN & 5 & 250000 \\
\hline
\end{tabular}

\begin{tabular}{|c|c|c|c|}
\hline CODE & SS MIN & SS MID & SS MAX \\
\hline 1 & 121500 & 134980 & 14850 \\
\hline 2 & 150500 & 167182 & 1839 \\
\hline 3 & 179400 & 199384 & 2193 \\
\hline 4 & 208400 & 231586 & 2547 \\
\hline 5 & 237400 & 263788 & 2902 \\
\hline Band Width & $-10 \%$ & & 10 \\
\hline
\end{tabular}

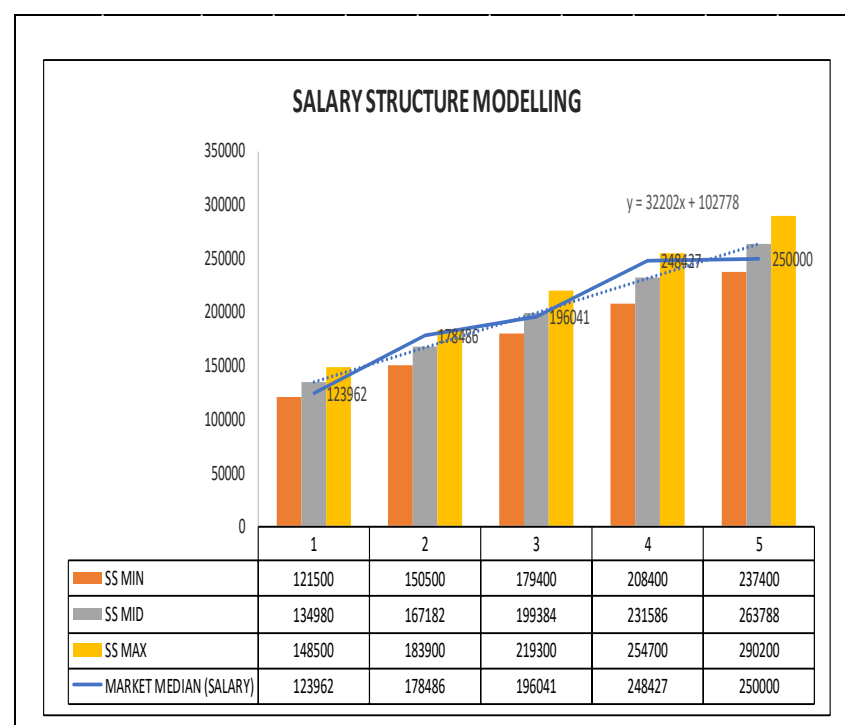

Graph 3 Salary Structure Modeling

\section{Findings: - Salary Structure Modelling}

Salary structure modelling assist in analysing the max and min pay an organization should be offering for a particular designation based upon market standards.

The trend analysis done in the study clearly showed that what promised was not delivered which led to employees leaving the organization. The study also thrown insights into the salary structure of the health care professionals which facilitates in better understanding of cost related measures and doing the needful for improving employee's morale.

\section{CONCLUSION}

We all are living in a VUCA environment of severe competition with companies jostling with each other for retaining the talent. This retention of talent assumes added importance given the equal accessibility availability and affordability of all other resources and the cutting edge which only the talented Human Resources could provide. This study emphasizes that new tools like HR Analytics AI and other statistical tools will help in providing much needed insights into the human behavior. And with these inputs organization could plan for sustainable HRM practices for recognizing rewarding and retention of talented human resources.

When the whole world is talking about Sustainability it's important for the organizations and more so for the health sector to use tools like HR Analytics for Sustainable HRM practices. So it's in the organizations interests in particular and of society in general that these advanced analytical tools are used to understand the human behavior better so that necessary initiatives could be taken by the HR departments for outstanding performance of their people.

Though PERSOLKELLY's 2019 H2 APAC Workforce Insights (21) revealed that increased use of automation and artificial intelligence at the workplace results in increased employee satisfaction organizations need to ally employees concern about loss of jobs. In other words, while increased use of technology in the form of HRA and Artificial Intelligence is called for better understanding the behavior for formulating and executing sustainable HRM practices employees are also required to be taken into confidence. In other words, people need to be involved informed about the likely benefits that accrue and inspire through transparency and integrity so that everyone in the HR department voluntarily applies and benefits the organization. In other words, it's not the acquisition of technology that matters but the way it is applied and adopted.

\section{Limitations}

While we try to look into how technology or collaboration between computers and HR could facilitate sustainable HRM practices we could not look into employees concerns about the use of technology. Because resistance from the employees might hinder application of technology.

\section{E. Future Scope}

Future research could look into this aspect as to how the employee's fears can be allayed. We can say that more than the type of technology to be adopted, the way the technology is applied and made it user friendly by taking the stakeholders into confidence matters a lot. Further, in future we will try to incorporate analytical tools into other areas of HRM especially with acquisition and retention of manpower.

\section{REFERENCES}

1. Boudreau J.W. Ramstad P.M. (2005) Talentship talent segmentation and sustainability: a new HR decision science paradigm for a new strategy definition. Human Resource Management 44(2):129-136

2. Marler, J. H., \& Boudreau, J. W. (2017). An evidencebased review of HR Analytics. The International Journal of Human Resource Management, 28(1), 3-26.

3. Fitz-Enz J. The new HR analytics - Predicting the economic value of your company's human capital investments American Management Association 2010

4. Fitz-Enz J. The ROI of Human Capital - Measuring the economic value of employee performance Amacom New York 2000 
5. Davenport, T. H., \& Dyché, J. (2013). Big data in big companies. International Institute for Analytics, 3.

6. https://blog.riverlogic.com/prescriptive-analytics-22things-the-experts-are-saying-about-analytics-risingstar,Accessed on 18 October: Time- 5:30 PM

7. https://www.dezyre.com/article/types-of-analyticsdescriptive-predictive-prescriptiveanalytics/209,Accessed on 18 October,2019: Time 5:30 PM

8. Hora, M. T., Bouwma-Gearhart, J., \& Park, H. J. (2017). Data driven decision-making in the era of accountability: Fostering faculty data cultures for learning. The Review of Higher Education, 40(3), 391-426.

9. https://www.persolkelly.com/page/resources-newsplatform/2019-apac-workforce-insights/Accessed on 18.9.2019 4:30 PM

10. Brewster C. (2002) Human resource practices in multinational companies. In: Martin J.G. Karen L.N. (eds) The Blackwell handbook of cross-cultural management. Blackwell Oxford pp. 126-141

11. Gobble Mary Anne M. Research Technology Management. Sep2017 Vol. 60 Issue 5 p59-61. 3p. DOI: 10.1080/08956308.2017.1348143. Database: Entrepreneurial Studies Source

12. Kramar Robin. International Journal of Human Resource Management. 2014 Vol. 25 Issue 8 p1069-1089. 21p. 2

13. Marler Janet H. Fisher Sandra L. Human Resource Management Review. Mar2013 Vol. 23 Issue 1 p18-36. 19p. DOI: 10.1016/j.hrmr.2012.06.002

14. Robert J. Zaugg Adrian Blum Norbert Thom. Berne: Sustainability in Human Resource Management IOPPress 2001 ISBN 3-906471-48-9

\section{AUTHORS PROFILE}

Dr A Jagan Mohan Reddy, is a Post- Graduate in Economics \& Management with a Law Degree and a PG Diploma in Industrial Relations \& Personnel Management. He is Ph.D in Management from Srikrishna Devaraya University,Anantapur,AP,India presently working as ProfessorHR at Symbiosis Institute of Business Management, Symbiosis International (,Deemed University).His research interests are Employee Engagement, Sustainability, Corporate Governance and Ethics in business.

Dr Ridhi Rani is a Certified HR analytics and metrics Professional (CHAMP), Assistant Professor (HR), at Symbiosis Institute of Business Management, Symbiosis International (Deemed University). She is Ph. D in Management from BRAB University, Muzzafarpur in Bihar. She has completed her MBA from Jaipuria Institute of Management, Luck now and Masters in Political Science from Faculty of Arts, Delhi University. Her research interests are HR analytics, Human Resource development, Compensation and benefits and Leadership.

Ms Varnika Chaudhary completed her Masters in Business administration with HR specialization from Symbiosis Institute of Business Management, Symbiosis International (,Deemed University). At present she is working with Biological E .Ltd as Management Trainee (Talent Management)(HR) 